\title{
Pilot Clinical Study of the Effects of Ginger Root Extract on Eicosanoids in Colonic Mucosa of Subjects at Increased Risk for Colorectal Cancer
}

\author{
Suzanna M. Zick, ${ }^{1,2 *}$ D. Kim Turgeon, ${ }^{3}$ Jianwei Ren, ${ }^{1}$ Mack T. Ruffin, ${ }^{1}$ Benjamin D. Wright, ${ }^{1}$ Ananda Sen, ${ }^{1}$ \\ Zora Djuric, ${ }^{1,2}$ and Dean E. Brenner ${ }^{3,4,5}$ \\ ${ }^{1}$ Department of Family Medicine, University of Michigan Medical School, Ann Arbor, Michigan \\ ${ }^{2}$ University of Micihgan School of Public Health Department of Enviromental Health Sciences, Ann Arbor, Michigan \\ ${ }^{3}$ Department of Internal Medicine, University of Michigan Medical School, Ann Arbor, Michigan \\ ${ }^{4}$ Department of Pharmacology, University of Michigan Medical School, Ann Arbor, Michigan \\ ${ }^{5}$ VA Medical Center, Ann Arbor, Michigan
}

Colorectal cancer (CRC) remains a significant cause of mortality. Inhibitors of cyclooxygenase (COX) and thus prostaglandin E2, are promising CRC preventives, but have significant toxicities. Ginger has been shown to inhibit COX, to decrease the incidence and multiplicity of adenomas, and decrease PGE2 concentrations in subjects at normal risk for CRC. This study was conducted to determine the effects of $2.0 \mathrm{~g} / \mathrm{d}$ of ginger given orally on the levels of PGE2, leukotriene B4 (LTB4), 13-hydroxy-octadecadienoic acids, and 5-, 12-, \& 15-hydroxyeicosatetraenoic acid, in the colonic mucosa of subjects at increased risk for CRC. We randomized 20 subjects to $2.0 \mathrm{~g} / \mathrm{d}$ ginger or placebo for $28 \mathrm{~d}$. At baseline and Day 28 , a flexible sigmoidoscopy was used to obtain colon biopsies. A liquid chromatography mass spectrometry method was used to determine eicosanoid levels in the biopsies, and levels were expressed per amount of protein or free arachidonic acid (AA). There was a significant decrease in AA between baseline and Day $28(P=0.05)$ and significant increase in LTB4 $(P=0.04)$ when normalized to protein, in subjects treated with ginger versus placebo. No other changes in eicosanoids were observed. There was no difference between the groups in total adverse events $(A E ; P=0.06)$. Ginger lacks the ability to decrease eicosanoid levels in people at increased risk for CRC. Ginger did appear to be both tolerable and safe; and could have chemopreventive effects through other mechanisms. Further investigation should focus on other markers of CRC risk in those at increased CRC risk. @ 2014 Wiley Periodicals, Inc.

Key words: cancer risk reductive; prostaglandins; lipoxygenase; inflammation; and zingiber

\section{INTRODUCTION}

Despite recent decreases in mortality, colorectal cancer (CRC) remains the third most prevalent and second most deadly cancer in the United States [1]. Non-steroidal anti-inflammatory drugs (NSAIDs), which inhibit cyclooxygenase $1 \& 2$ (COX-1 \& 2) enzymes and thus lower the levels of the inflammatory prostaglandin $\mathrm{E}_{2}\left(\mathrm{PGE}_{2}\right)$ are promising colorectal cancer (CRC) chemopreventive agents [2]. However, the gastrointestinal and cardiovascular side-effects of aspirin and other NSAIDs have raised concerns for their daily prescription to an otherwise healthy population $[3,4]$. Also, there is some thought that the inhibition of COX enzymes by these drugs could cause the shunting of arachidonic acid (AA), the substrate for COX, towards the production of other inflammatory eicosanoids [5]. In particular, various eicasanoids produced by the lipoxygenase (LOX) enzymes (5-, 12-, \& 15-LOX) from AA, which are leukotriene $\mathrm{B}_{4}\left(\mathrm{LTB}_{4}\right)$ and the hydroxyeicosatetraenoic acids (HETEs), 5-, 12-, \& 15-HETE and 13hydroxyoctadecadienoic acid (13-HODE) produced from linoleic acid. Leukotriene $\mathrm{B}_{4}$ and 5- \& 12-HETE
Abbreviations: CRC, colorectal cancer; COX, cyclooxygenase; $\mathrm{PGE}_{2}$ prostaglandin $\mathrm{E}_{2} ; \mathrm{LTB}_{4}$, leukotriene $\mathrm{B}_{4} ;$ 13-HODE, 13-hydroxy-octadecadienoic acids; 5-, 12-, \& 15-HETE, 5-, 12-, \& 15-hydroxyeicosatetraenoic acid; $A A$, arachidonic acid; $A E$, adverse events; NSAIDs, nonsteroidal anti-inflammatory drugs; COX-1 \& 2, cyclooxygenase $1 \& 2$; LOX, lipoxygenase; 5-, 12-, \& 15-LOX, enzymes; HETES, hydroxyeicosatetraenoic acids; MCRU, University of Michigan Clinical Research Unit; IDS, Investigational Drug Service; NCl, National Cancer Institute; LC/MS/MS, reverse-phase LC electrospray ionization mass spectrometry; ng, nanogram; mg, milligram; $\mu \mathrm{g}$, microgram; SD, standard deviations.

Conflict of interest: none.

ClinicalTrials.gov Identifier: NCT01344538.

Grant sponsor: National Cancer Institute (NCI); Grant numbers: P30 CA047904; P30 CA 48592; K24 CA80846; K07CA102592 Grant sponsor: University of Michigan Clinical Research Center: Grant number: UL1RR024986; Grant sponsor: Kutsche Family Memorial Endowment

*Correspondence to: 24 Frank Lloyd Wright Drive, Lobby M, P.O. Box 375, University of Michigan Medical Center, Ann Arbor, M 48105.

Received 10 December 2013; Revised 21 March 2014; Accepted 27 March 2014

DOI 10.1002/mc.22163

Published online 24 April 2014 in Wiley Online Library (wileyonlinelibrary.com). 
have all been implicated in the development of CRC [6-12], while both 15-HETE and 13-HODE appear to have anti-inflammatory and anti-tumorigenic activities [13-15]. Therefore, using natural nutritional components with low toxicity, which have the potential to affect COX and LOX, and their products is a potential area of investigation for the prevention of CRC.

One such natural nutritional compound is ginger root (Zingiber officinale), which has been shown to inhibit 5-LOX [16-19] and COX-1 \& -2 [18,20-22]. Ginger root decreases inflammation in various $\mathrm{mu}-$ rine models [16,23-26], and reduces serum concentrations of $\mathrm{PGE}_{2}$ in rats [27]. Ginger root has also demonstrated preventative effects by decreasing tumor size, incidence and multiplicity in chemically induced animal models of colon carcinogenesis [2830]. When ginger was administered in the postinitiation stage, it did not suppress aberrant crypt foci formation nor did ginger significantly change the proliferative or apoptotic indexes of the colonic crypt [31]. In our recent studies in participants at normal and increased risk for CRC we found that ginger significantly lowered COX-1 protein expression in increased risk participants, but not in normal risk participants [32]. In another study, ginger significantly reduced gut tissue concentrations of $\mathrm{PGE}_{2}$ and 5-HETE and with a trend toward significant decreases in 12-HETE and 15-HETE in participants at normal risk for CRC [33].

The purpose of this study was to expand on our previous work in subjects at normal risk for CRC by examining the effect of $2.0 \mathrm{~g}$ of ginger taken daily for 28 days compared to placebo on eicosanoids in the colonic mucosa of subjects at increased risk for developing colorectal cancer. Secondary objectives were to evaluate the safety, tolerability, adherence and blinding of ginger supplementation.

\section{MATERIALS AND METHODS}

\section{Study Participants}

Fliers and word-of mouth were used to recruit 21 participants from the Ann Arbor, MI area between June 2009 and January 2010. Eligible participants had to be generally healthy individuals 18 years or older, who were at increased risk for CRC defined as having at least one of the following: (1) a first degree relative with CRC before the age of 60; (2) a previous adenomatous polyp; (3) or early stage resected (Dukes A, B, or C) colon cancer. Subjects were excluded if they were: lactose intolerant; had a diagnosis of peptic ulcer disease, gastrointestinal bleeding, or gastrin secreting tumors; had a known allergy to ginger; were taking supplements or medications which could obscure the ability to detect anti-inflammatory effects; and pregnant or lactating women. Also persons with hereditary non-polyposis colon cancer or familial adenomatous polyposis (HNPCC/FAP), inflammatory bowel disease, or coagulopathy disorders were excluded. Participants were told to stop eating any foods containing ginger within 14 days before drug administration and given a list of gingerrich foods to avoid. All participants were reimbursed for their time.

The University of Michigan Institutional Review Board approved this study and all participants gave written, informed consent before beginning any study procedures. This study was conducted at the University of Michigan Clinical Research Unit (MCRU).

\section{Ginger Intervention}

Details on quality control of the ginger extract have been previously published [33]. Briefly, a $2.0 \mathrm{~g}$ dose of powered ginger root extract (Z. officinale) standardized to $15 \mathrm{mg}(5 \%)$ of total gingerols and manufactured by Pure Encapsulations ${ }^{\circledR}$ (Sudbury, MA) was used in the study. This was the same ginger product used in our previous trials with identical amount (5\%) of total gingerols. The $2.0 \mathrm{~g}$ dose of ginger was based on the maximum tolerated dose of ginger in a phase 1 study in healthy volunteers [34]. Lactose was used for the placebo capsules. Both the lactose and ginger powder were placed into identical opaque red capsules by the Investigational Drug Service (IDS) of the University of Michigan.

Toxicity of the intervention was evaluated at weekly intervals using The National Cancer Institute (NCI) Common Toxicity Scale V 4.02 [35].

\section{Randomization, Allocation, Adherence, and Blinding}

Participants were randomized equally into the placebo or ginger group. The study biostatistician generated the randomization code, which was kept by the University of Michigan IDS. The next available randomization number was assigned by the IDS as eligible participants were identified. Participants and study personnel were unaware of the randomization list or treatment assignment. To determine if participants were blind to treatment allocation, participants were asked at their final visit which treatment they received ("ginger," "placebo" or "don't know").

Adherence was assessed by weekly telephone calls, self-report, and pill counts at the end of the study. Adherence was defined as taking at least $70 \%$ of capsules as prescribed.

\section{Flexible Sigmoidoscopy and Tissue Collection}

Two flexible sigmoidoscopies, one at baseline and the second within $24 \mathrm{~h}$ of the last ginger/placebo dose on Day 28 were performed. Participants were not asked to fast or to undergo any bowel cleansing preparation. Participants were placed in a left lateral decubitus position and a flexible sigmoidoscope was passed at least $15 \mathrm{~cm}$ above the anal sphincter and eight tissue samples were obtained. Each biopsy specimen was taken $2 \mathrm{~cm}$ or more from other biopsy 
sites in the distal sigmoid colonic mucosa by opening and pressing the biopsy forceps perpendicular to the mucosal surface with mild pressure.

\section{Tissue Handling and Disposition}

Biopsies were frozen in liquid nitrogen and then stored at $-70^{\circ} \mathrm{C}$ after being placed into a sterile $1.5-\mathrm{mL}$ Eppendorf tube. Biopsy samples were taken at precisely $50 \mathrm{~s}$ after the time the biopsy forceps were closed. Biopsies weighed approximately $5 \mathrm{mg}$ and contained between 400 and $600 \mu \mathrm{g}$ protein. Eicosanoids assays were run in triplicate and required around $10-20 \mu \mathrm{g}$ of colon tissue, which is the equivalent of two biopsies.

\section{Analytical Methods}

Eicosanoids (PGE 2 , 5-HETE, 12-HETE, 15-HETE and 13HODE)

Eicosanoids were assayed according to previously reported methods [33,36,37] Briefly, reverse-phase LC electrospray ionization mass spectrometry (LC/ $\mathrm{MS} / \mathrm{MS}$ ) analyses were used for quantitation of $\mathrm{PGE}_{2}$, $\mathrm{LTB}_{4}$, 5-HETE, 12-HETE, 15-HETE, and 13-HODE. LC/ MS/MS analyses were performed using a Quattro Ultima tandem mass spectrometer (Micromass, Beverly, MA) equipped with an Agilent HP 1100 binary pump HPLC inlet. Eicosanoids were separated using a Luna $3 \mu$ Phenyl-Hexyl $2 \mathrm{~mm} \times 150 \mathrm{~mm}$ LC column (Phenomenex, Torrance, CA). The mobile phase consisted of $10 \mathrm{mM}$ ammonium acetate $(\mathrm{pH}$ 8.5) and methanol. For the analysis of PGE 2 , HETEs, and 13-HODE, the separation was achieved using a linear methanol gradient from $40 \%$ to $60 \%$ over 18 min followed by a methanol flush. The flow rate was $250 \mu \mathrm{L} / \mathrm{min}$ with a column temperature of $50^{\circ} \mathrm{C}$. The sample injection volume was $25 \mu \mathrm{L}$. Samples were kept at $4^{\circ} \mathrm{C}$ during the analysis. All eicosanoids were detected using electrospray negative ionization and multiple-reaction monitoring of the transition ions for the metabolites and their internal standards [38].

The mass spectrometer (Thermo Finnigan TSQ Quantum, San Jose, CA) was operated in the electrospray negative ion mode with a cone voltage of $2300 \mathrm{~V}$, a cone gas flow rate of $117 \mathrm{l} / \mathrm{h}$, and a devolution gas flow rate of $9981 / \mathrm{h}$. The temperature of the desolvation region was $350^{\circ} \mathrm{C}$, and the temperature of the source region was $120^{\circ} \mathrm{C}$. Fragmentation for all compounds was performed using argon as the collision gas at a collision cell pressure of $2.10 \times 10^{-3}$ Torr. The collision energy ranged from 16 to $31 \mathrm{~V}$ depending on the analyte. The results were either expressed as nanogram (ng) of eicosanoid per milligram (mg) of protein or as ng of eicosanoid per microgram $(\mu \mathrm{g})$ of free AA. All of the biopsy samples from a given individual were assayed in the same batch to eliminate any batch effects over time.

\section{Statistical Methods and Sample Size}

Statistical analyses were conducted using SAS 9.2 statistical software (SAS Institute Inc., Cary, NC). A Pvalue $\leq 0.05$ (two-sided) was considered statistically significant. Baseline characteristics stratified by treatment group were analyzed and reported as mean \pm standard deviations (SD) for continuous variables, and as counts and percentages for categorical variables. Balance between treatment groups on baseline characteristics was tested using independent sample $t$ tests for continuous variables and Pearson's Chisquare and Fisher exact tests, as appropriate, for categorical variables.

We calculated the mean percent change within treatment group, for $\mathrm{PGE}_{2}, \mathrm{LTB}_{4}, 5$-HETE, 12-HETE, 15-HETE, and 13-HODE from baseline to Day 28. Results are reported as mean $\pm \mathrm{SD}$. Pearson's Chisquare or Fisher's exact test were used to calculate between group differences for adverse events.

Assessment of blinding and adherence were determined using an independent sample $t$-test to determine the difference in the proportion of participants in each group who correctly guessed their correct group assignment or who took $70 \%$ or greater of their study medication. Mean and SD for percent adherent per group was tested using independent sample $t$-test.

We determined using a two sample t-test that a sample size of 10 per treatment group would have better than $80 \%$ power and a $5 \%$ level of significance to detect a reduction of at least $25 \%$ mean difference in $\mathrm{PGE}_{2}$ mucosal concentration in the ginger group compared to the placebo group at the end of a $28 \mathrm{~d}$ intervention. This is based on previously reported data on $\mathrm{PGE}_{2}$ levels in participants at increased risk of CRC human colon tissue who had baseline $\mathrm{PGE}_{2}$ mucosal concentrations of $14.4, \pm 1.7 \mathrm{pg} / \mu \mathrm{g}$ protein, which decreased after $28 \mathrm{~d}$ of $81 \mathrm{mg}$ of asprin to a mean concentration of $4.7 \pm 0.70 \mathrm{pg} / \mu \mathrm{g}$ protein which was roughly a $70 \%$ reduction compared to the placebo group [39].

\section{RESULTS}

\section{Subjects and Toxicity}

We screened 47 persons of whom 21 met all eligibility criteria and were randomized: 11 to placebo and 10-2.0 g ginger, for $28 \mathrm{~d}$. However, one participant randomized to the placebo group was removed from study after it was determined that he was not at increased risk for CRC. Figure 1 documents the numbers of participants, reasons for exclusions and reasons for discontinuing the intervention.

Table 1 reports demographic and clinical characteristics by group. No significant differences for any demographic or clinical characteristic between treatment groups were found. The mean age of the study subjects was $51.0 \pm 12.9$ (range 29-73 yr) with less 


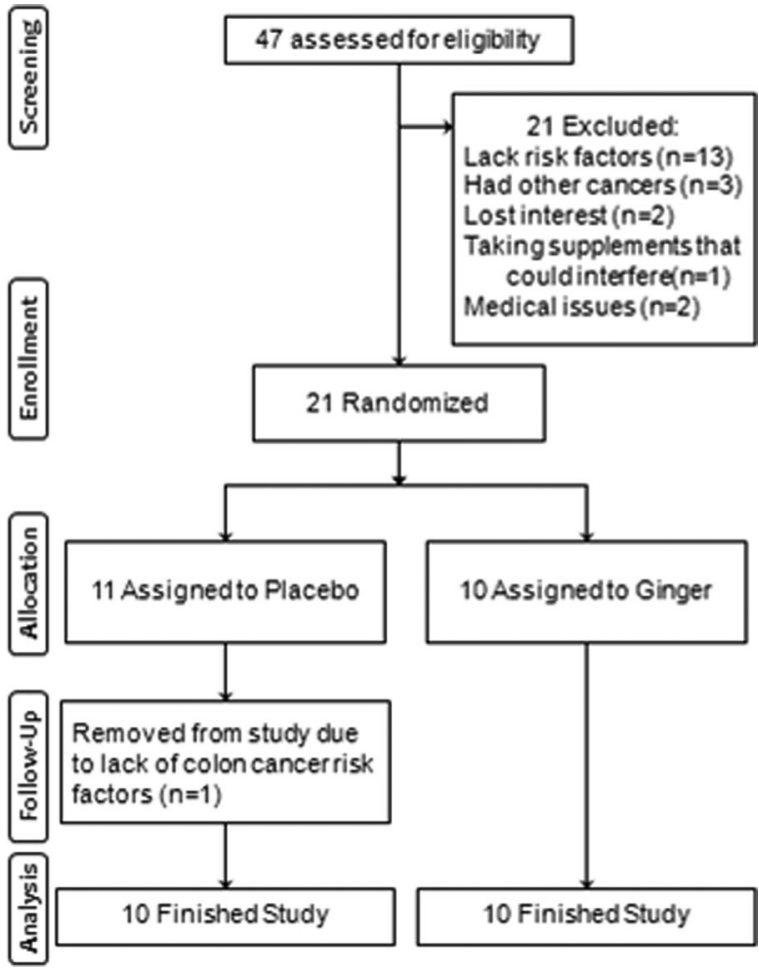

Figure 1. Flow diagram of a trial of ginger supplementation over 4 wk on eicosanoids in normal-appearing colorectal mucosa of individuals at increased risk of for colorectal cancer

than half of the participants being male $(N=7$, $35.0 \%)$. The majority of the participants self-reported as being Caucasian $(N=15,75.0 \%)$, with two $(25 \%)$ indicating that they were African American $(N=2)$, American Indian $(N=2)$, or mixed race $(N=1)$, while none of the participants reported being of Hispanic

Table 1. Baseline Characteristics of the Randomization Groups

\begin{tabular}{|c|c|c|c|}
\hline Characteristics & $\begin{array}{c}\text { Ginger } \\
(N=10)\end{array}$ & $\begin{array}{l}\text { Placebo } \\
(N=10)\end{array}$ & $P$-value \\
\hline \multicolumn{4}{|l|}{ Sex, no. (\%) } \\
\hline Men & $4(40)$ & $3(30)$ & $0.64^{a}$ \\
\hline Women & $6(60)$ & $7(70)$ & \\
\hline \multicolumn{4}{|l|}{ Race, no. (\%) } \\
\hline White & $8(80)$ & $7(70)$ & $0.38^{a}$ \\
\hline Age, mean (SD), yr & $51.1(11.7)$ & $50.8(14.6)$ & $0.95^{b}$ \\
\hline \multicolumn{4}{|c|}{ Reason for being high risk for $\mathrm{CRC}^{\mathrm{C}}$, no. (\%) } \\
\hline First degree relative ${ }^{d}$ & $4(40.0)$ & $6(60.0)$ & $0.47^{b}$ \\
\hline Previous adenoma & $5(50.0)$ & $4(40.0)$ & \\
\hline Previous CRC & $1(10.0)$ & $0(0.0)$ & \\
\hline
\end{tabular}

${ }^{\mathrm{a}} P$-value is based on an independent samples $t$-test.

${ }^{\mathrm{b}} P$-value is based on a Chi-Squared.

${ }^{\mathrm{C}} \mathrm{CRC}$, colorectal cancer.

${ }^{\mathrm{d}}$ First degree relative diagnosed with colorectal cancer before the age of $60 \mathrm{yr}$. ethnicity. The majority of participants $(N=10$, $50.0 \%)$ were at increased risk for CRC due to having had a prior adenoma $(N=12,60.0 \%)$, and seven subjects had a first degree relative with a diagnosis of CRC before the age of 60 . Only one participant had a history of early stage colon cancer $(5 \%)$, and three participants had multiple reasons (both a prior adenoma and a first degree relative) for being at increased colon cancer risk.

Possible, probably or likely treatment-related toxicities are reported by participants in Table 2. All adverse events were non-serious and reported as grade 1 per the NCI Common Toxicity Criteria (v. 4.02) [35]. No significant difference was observed between the groups for total adverse events $(N=13, P=0.06)$ or among specific categories of adverse events such as gastrointestinal (GI) toxicities $(N=10, P=0.18)$.

Eicosanoids (PGE $2, \mathrm{LTB}_{4}, 5-\mathrm{HETE}, 12-\mathrm{HETE}, 15-\mathrm{HETE}$, and 13-HODE)

In Table 3, all continuous outcomes and mean percent change from baseline to Day 28 of $\mathrm{PGE}_{2}, \mathrm{LTB}_{4}$, 5-, 12-, 15-HETE, 13-HODE, and AA are shown normalized to both protein and $\mathrm{AA}$, with the exception of AA. The baseline values of $\mathrm{PGE}_{2}, \mathrm{LTB}_{4}$, 5-HETE, 12-HETE, 15-HETE, and 13-HODE in colon biopsies across both groups were $11.8 \pm 12.8$, $2.60 \pm 1.7, \quad 6.3 \pm 6.3, \quad 2.7 \pm 1.8, \quad 10.1 \pm 13.6, \quad$ and $47.2 \pm 77.5 \mathrm{pg} / \mu \mathrm{g}$ protein, respectively (mean $\pm \mathrm{SD}$, $n=20$ ). Baseline values normalized to $\mathrm{AA}$ of $\mathrm{PGE}_{2}$, $\mathrm{LTB}_{4}$, 5-HETE, 12-HETE, 15-HETE, and 13-HODE were $1.4 \pm 1.2,0.5 \pm 0.7,1.9 \pm 5.0,0.5 \pm 0.6,1.9 \pm 3.2$, and $4.9 \pm 8.1 \mathrm{ng} / \mu \mathrm{g}$, respectively.

There was no significant difference in mean percent change between the placebo and ginger group for any of the eicosanoids when normalized to AA after $28 \mathrm{~d}$. In contrast, when normalized to protein there was a significant increase $(P=0.04)$ in $\mathrm{LTB}_{4}$ in the ginger group $(-4.7 \pm 54.9 \%$ placebo versus $54.0 \pm 63.2 \%$ ginger) and a significant $(P=0.05)$ decrease in AA in the ginger group $(229.4 \pm 413.7 \%$ placebo versus $-44.2 \pm 41.5 \%$ ginger). There were no other significant differences in the other eicosanoids.

Table 2. Adverse Events Reported by Person

\begin{tabular}{lccc}
\hline Adverse Events & $\begin{array}{c}\text { Ginger } \\
(n=10)\end{array}$ & $\begin{array}{c}\text { Placebo } \\
(n=10)\end{array}$ & $P$-value $^{a}$ \\
\hline $\begin{array}{l}\text { All participants with } \\
\quad \text { any AE, No. (\%) }\end{array}$ & $9(90.0)$ & $4(40.0)$ & 0.06 \\
CGI $^{\text {b }}$ & $7(70.0)$ & $3(30.0)$ & 0.18 \\
Other $^{c}$ & $3(30.0)$ & $1(10.0)$ & 0.58
\end{tabular}

${ }^{a} P$-value: Chi-Square or Fisher's exact test as appropriate.

${ }^{b}$ GI symptoms includes: bloating, urgency, gas, nausea, heartburn, sores in mouth \& anorexia.

${ }^{\mathrm{C}}$ Other includes: allergic reaction, nose bleed, skin rash, struck with water tube after biopsy procedure. 
Table 3. Eicasanoids Levels in Normal Mucosa in Participants at Increased Risk for Colorectal Cancer [Mean (SD)*]

\begin{tabular}{|c|c|c|c|c|c|c|c|}
\hline \multirow[b]{2}{*}{ Eicosanoid } & \multicolumn{3}{|c|}{ Placebo $(n=10)$} & \multicolumn{3}{|c|}{ Ginger $(n=10)$} & \multirow[b]{2}{*}{$P$-value ${ }^{a}$} \\
\hline & Baseline & After $28 \mathrm{~d}$ & Mean $\%$ change $^{b}$ & Baseline & After $28 d$ & Mean \% change ${ }^{b}$ & \\
\hline \multicolumn{8}{|c|}{ Standardized to protein $(\mathrm{pg} / \mu \mathrm{g})$} \\
\hline $\mathrm{PGE}_{2}$ & $12.9(15.2)$ & $12.8(16.8)$ & $37.0(113.4)$ & $10.6(10.5)$ & $23.6(21.2)$ & $333.5(773.6)$ & 0.26 \\
\hline $\mathrm{LTB}_{4}$ & $2.9(1.7)$ & $2.6(2.1)$ & $-4.7(54.9)$ & $2.4(1.9)$ & $3.5(2.3)$ & $54.0(63.2)$ & 0.04 \\
\hline HETE5 & $8.9(8.0)$ & $9.0(8.0)$ & $39.1(108.9)$ & $3.7(2.0)$ & $15.2(14.0)$ & $412.1(755.6)$ & 0.16 \\
\hline HETE12 & $3.2(2.2)$ & $5.1(5.5)$ & $59.4(149.1)$ & $2.2(1.3)$ & $4.5(4.4)$ & $101.7(196.1)$ & 0.60 \\
\hline HETE15 & $14.7(17.7)$ & $11.1(9.8)$ & $82.1(189.5)$ & $5.5(5.6)$ & $20.6(18.8)$ & $602.5(1047.8)$ & 0.16 \\
\hline HODE13 & $41.4(50.8)$ & $30.9(22.0)$ & $27.7(105.2)$ & $53.0(100.1)$ & $35.0(32.6)$ & $55.7(122.4)$ & 0.59 \\
\hline AA $(n g / p g)^{c}$ & $1.0(1.3)$ & $1.4(1.4)$ & $229.4(413.7)$ & $1.6(1.1)$ & $0.7(0.4)$ & $-44.2(41.5)$ & 0.05 \\
\hline \multicolumn{8}{|c|}{ Standardized to arachidonic acid ( $\mathrm{ng} / \mu \mathrm{g}$ ) } \\
\hline $\mathrm{PGE}_{2}$ & $1.7(1.4)$ & $3.70(8.4)$ & $147.6(368.7)$ & $1.0(1.0)$ & $3.0(2.9)$ & 1149.2 (3194.5) & 0.17 \\
\hline $\mathrm{LTB}_{4}$ & $0.7(1.0)$ & $0.34(0.3)$ & 84.3 (205.9) & $0.2(0.2)$ & $0.5(0.4)$ & $173.8(248.9)$ & 0.27 \\
\hline HETE5 & $3.4(6.9)$ & $1.72(2.5)$ & 362.7 (718.9) & $0.4(0.3)$ & $2.4(3.7)$ & 1079.6 (2297.0) & 0.15 \\
\hline HETE12 & $0.7(0.7)$ & $0.57(0.5)$ & 247.1 (598.9) & $0.2(0.1)$ & $0.6(0.7)$ & $279.2(487.4)$ & 0.38 \\
\hline HETE15 & $3.3(4.1)$ & $2.00(3.2)$ & 290.6 (545.8) & $0.5(0.5)$ & $3.2(5.2)$ & 1406.3 (2993.3) & 0.13 \\
\hline HODE13 & 6.8 (10.9) & $4.98(6.3)$ & $140.5(453.7)$ & $3.1(3.4)$ & $4.4(4.5)$ & $114.1(164.02)$ & 0.23 \\
\hline
\end{tabular}

*SD, \pm standard deviation.

${ }^{a}$ Independent $t$-test of the difference between the mean percent change from baseline to Day 28.

${ }^{b}$ Mean percent change between baseline and Week 4 is calculated as [(eicosanoid at time 2/eicosanoid at time 1)/eicosanoid at time 1)] per participant and then an average is obtained. Mean percent change may not appear reflective of change in baseline and 28-d follow-up mean values. This is due to the large amount of variability in the baseline measures.

${ }^{\mathrm{c}} \mathrm{AA}$, arachidonic acid; PGE2, prostaglandin $\mathrm{E}_{2}$; 5-HETE, 12-HETE, 15-HETE, 5-, 12- \& 15-hydroxyeicosatetraenoicacid; 13-HODE, 13-hydroxy-octadecadienoic acids.

\section{Blinding and Adherence}

Participants were unable to determine whether they had received ginger or placebo $(P=0.53)$. The majority of participants $(N=9,45.0 \%)$ indicated they were taking placebo, with seven participants reporting ginger $(35.0 \%)$ and four $(20.0 \%)$ being unable to decide to which treatment they were randomized.

Participants on average took $79.1 \pm 7.4 \%$ of their capsules and all participants were adherent per our definition of taking at least $70 \%$ of their capsules with a mean \pm SD of $78.4 \pm 8.6 \%$ in the placebo group and $79.8 \pm 6.6 \%$ in the ginger group. There was no significant difference in adherence between treatment groups $(P=0.70)$.

\section{DISCUSSION}

We found that ingesting $2.0 \mathrm{~g}$ per $\mathrm{d}$ of ginger root extract for $28 \mathrm{~d}$ significantly decreased AA and significantly increased concentrations of $\mathrm{LTB}_{4}$, when normalized to protein, in normal appearing gut mucosa in participants who were at increased risk of developing colon cancer. Ginger had no significant effect on any other eicosanoid including $\mathrm{PGE}_{2}$ in gut tissue whether normalized to protein or AA. Although not statistically significant, the concentrations of all eicosanoids were increased, and in some cases to a large extent, in the ginger treatment group compared to the placebo group at the end of a $28 \mathrm{~d}$ intervention using either method of normalization. Of import, however, mean percent increases in eicosanoid concentrations were accompanied by a high level of variability implying that the response to ginger was highly heterogeneous with some participants experiencing no change, others decreases in and others large increases in eicosanoid concentrations.

These findings are in contrast to previous studies in humans as well as those conducted in a rat model and in vitro. Whole ginger root and various ginger constituents have been shown to inhibit leukotriene synthesis by blocking 5-LOX activity [21,40], reduce COX-1 and COX-2 activity and subsequently reduce concentrations of $\mathrm{PGE}_{2}$ in a variety of cell lines [2022,41-47], and significantly reduce serum levels of $\mathrm{PGE}_{2}$ in female Sprague-Dawley rats given $50 \mathrm{mg} / \mathrm{kg}$ ginger extract daily [27]. Our previous work in participants at normal risk for CRC showed that a $2.0 \mathrm{~g}$ dose of ginger root extract given for $28 \mathrm{~d}$ significantly reduced $\mathrm{PGE}_{2}$ concentrations in colonic mucosa [33]. We also demonstrated that COX-1 protein expression was significantly reduced in participants at increased risk for CRC (those reported on, in this study), although it remained unchanged in participants at normal risk [32]. In contrast, a study by Black and colleagues saw no significant difference in plasma $\mathrm{PGE}_{2}$ levels in healthy volunteers after $28 \mathrm{~d}$ of taking $2.0 \mathrm{~g}$ of either raw or heat treated ginger root [48]. Different to previous studies, but in agreement with our results, a study in 21 people with knee and hip osteoarthritis found that $28 \mathrm{~d}$ of ingesting a $340 \mathrm{mg}$ of a standardized ginger extract (EV.EXT 35) significantly increased levels of several prostaglandins including $\mathrm{PGE}_{2}$ in the stomach mucosa [49]. 
Differences between these various studies could be due to different doses and formulations of the ginger products, the absorption and metabolism of ginger in in vivo environments; or differential effects of ginger on different tissue types or in situations of underlying inflammation. A clear challenge with natural health products, such as ginger, is the heterogeneity of ginger preparations. A few in vitro studies have shown significant differences between various ginger constituents in impacting COX enzyme activity and $\mathrm{PGE}_{2}$ production $[22,42,46]$. However, systematic differences in structure and function of various ginger constituents have not been examined in animal models or humans, thus making it unclear if different ginger formulations would behave differently in in vivo situations.

Underlying the importance of examining the effect of ginger in humans and on tissues of interest is the possible differential effects of ginger on different tissue cell types or in situations of underlying inflammation. While ginger and its components appear to decrease the production of inflammatory products such as $\mathrm{PGE}_{2}$ and $\mathrm{LTB}_{4}$, many of these studies were conducted in isolated cell lines and quite a few in murine macrophages (RAW 264.7) using lipopolysaccharide (LPS)-elicited production of $\mathrm{PGE}_{2}$. In vitro studies such as these are useful for exploring possible mechanisms, but they do not model the complex biological interactions that occur in animals or humans. For instance the study by Drozdov and colleagues [49] found that $\mathrm{PGE}_{2}$ and related eicosanoids were elevated in gastric tissue after ginger consumption and they also found an increased concentration of $\mathrm{PGE}_{2}$ in the gastric mucosa.

Another interpretation of our findings, if eciosanoids are good biomarkers of CRC risk, is that ginger may not be an effective CRC prevention agent. Alternately, although a controversial idea, is that inhibition of inflammatory eciosanoids may not equate with prevention of CRC. There is a robust and growing body of evidence that NSAIDs may not act via their conventional anti-COX effects for colon cancer prevention [50]. Consequently, it may be more fruitful for future investigations to focus on ginger's effect on underlying biological pathways rather than basing ginger's evaluation on biochemistry such as eicosanoid levels. Numerous in vitro studies have shown significant impacts on various cell cycle markers [51,52]. Moreover, research in people at increased risk of CRC have demonstrated significant effects of ginger on proliferation, differentiation, and apoptosis markers [53].

This study had several limitations, which include a small sample size, a short intervention period, and a fairly large amount of variability in eicosanoid levels. This was intended to be a pilot study for a larger human trial. Thus, it is possible that extended ginger consumption and more study participants might provide additional power to detect the effects of dietary ginger root intake on various prostaglandin pathways. Further, the small sample size did not allow us to conduct additional subgroup analyses by risk type, for example, family history, previous adenoma, previous CRC nor by sociodemographic variables such as age, race, and gender. This study would need to be further replicated in larger trials, which would have adequate power to examine several independent groups defined by baseline colonic mucosal eicosanoid concentrations to account for the presence of low levels of inflammation. Also, future studies may need to focus on outcomes with less variability than tissue eicosanoids such as proliferation, differentiation, and apoptosis markers, which have already been demonstrated to be significantly affected in humans by ginger [53].

In summary, $28 \mathrm{~d}$ of supplementation with ginger root extract in participants who were at increased risk for CRC caused a significant decrease in normal colonic mucosa of AA and significantly increased concentrations of $\mathrm{LTB}_{4}$, when normalized to protein. Ginger had no significant effect on any other eicosanoid including $\mathrm{PGE}_{2}$ in colon tissue whether normalized to protein or AA. Ginger did increase eicasanoids other than $\mathrm{PGE}_{2}$, as compared to placebo, when normalized to either AA or protein, but these increases were not statistically significant. Future, larger studies with ginger supplementation should perhaps focus on other biomarker outcomes.

\section{ACKNOWLEDGMENTS}

The ginger extract was generously donated by Pure Encapsulations ${ }^{\circledR}$ (Sudbury, MA). We would also like to thank Kate Brummett for assistance with figures. Research reported in this publication was supported by National Cancer Institute of the National Institutes of Health under award number P30 CA047904, P30 CA 48592, K24 CA80846, and K07CA102592 from the National Cancer Institute (NCI) and University of Michigan Clinical Research Center UL1RR024986, and the Kutsche Family Memorial Endowment. The content is solely the responsibility of the authors and does not necessarily represent the official views of the National Institutes of Health.

\section{REFERENCES}

1. Siegel R, Naishadham D, Jemal A. Cancer statistics, 2013. CA Cancer J Clin 2013:63:11-30.

2. Elwood PC, Gallagher AM, Duthie GG, Mur LA, Morgan G. Aspirin, salicylates, and cancer. Lancet 2009;373:1301-1309.

3. Solomon SD, McMurray JJ, Pfeffer MA, et al. Cardiovascular risk associated with celecoxib in a clinical trial for colorectal adenoma prevention. N Engl J Med 2005;352:1071-1080.

4. James MW, Hawkey CJ. Assessment of non-steroidal antiinflammatory drug (NSAID) damage in the human gastrointestinal tract. Br J Clin Pharmacol 2003;56:146-155.

5. Cianchi F, Cortesini C, Fantappie O, et al. Cyclooxygenase-2 activation mediates the proangiogenic effect of nitric oxide in colorectal cancer. Clin Cancer Res 2004;10:2694-2704.

6. Bortuzzo C, Hanif R, Kashfi K, Staiano-Coico L, Shiff SJ, Rigas B. The effect of leukotrienes $B$ and selected HETEs on the 
proliferation of colon cancer cells. Biochim Biophys Acta 1996;1300:240-246.

7. Nielsen CK, Campbell JI, Ohd JF, et al. A novel localization of the G-protein-coupled CysLT1 receptor in the nucleus of colorectal adenocarcinoma cells. Cancer Res 2005;65:732-742.

8. Tong WG, Ding XZ, Talamonti MS, Bell RH, Adrian TE. LTB4 stimulates growth of human pancreatic cancer cells via MAPK and Pl-3 kinase pathways. Biochem Biophys Res Commun 2005;335:949-956

9. Soumaoro LT, lida $S$, Uetake $H$, et al. Expression of 5lipoxygenase in human colorectal cancer. World J Gastroenterol 2006;12:6355-6360.

10. Melstrom LG, Bentrem DJ, Salabat MR, et al. Overexpression of 5-lipoxygenase in colon polyps and cancer and the effect of 5LOX inhibitors in vitro and in a murine model. Clin Cancer Res 2008; 14:6525-6530.

11. Ihara A, Wada K, Yoneda M, Fujisawa N, Takahashi H, Nakajima A. Blockade of leukotriene B4 signaling pathway induces apoptosis and suppresses cell proliferation in colon cancer. J Pharmacol Sci 2007;103:24-32.

12. Gao P, Guan L, Zheng J. Role of leukotriene B4 in celecoxibmediated anticancer effect. Biochem Biophys Res Commun 2010;402:308-311.

13. Bhattacharya S, Mathew G, Jayne D, Pelengaris S, Khan M. 15Lipoxygenase-1 in colorectal cancer: A review. Tumor Biol 2009;30:185-199.

14. II Lee S, Zuo X, Shureiqi I. 15-Lipoxygenase-1 as a tumor suppressor gene in colon cancer: Is the verdict in? Cancer Metastasis Rev 2011;30:481-491.

15. Shureiqi I, Chen D, Day RS, et al. Profiling lipoxygenase metabolism in specific steps of colorectal tumorigenesis. Cancer Prev Res (Phila) 2010;3:829-838.

16. Mascolo N, Jain R, Jain SC, Capasso F. Ethnopharmacologic investigation of ginger (Zingiber officinale). J Ethnopharmacol 1989;27:129-140.

17. Kiuchi F, Shibuya M, Sankawa U. Inhibitors of prostaglandin biosynthesis from ginger. Chem Pharm Bull (Tokyo) 1982;30:754-757.

18. Koo KL, Ammit AJ, Tran VH, Duke CC, Roufogalis BD. Gingerols and related analogues inhibit arachidonic acidinduced human platelet serotonin release and aggregation. Thromb Res 2001;103:387-397.

19. Sharma JN, Srivastava KC, Gan EK. Suppressive effects of eugenol and ginger oil on arthritic rats. Pharmacology 1994; 49:314-318.

20. Nurtjahja-Tjendraputra E, Ammit AJ, Roufogalis BD, Tran VH, Duke CC. Effective anti-platelet and COX-1 enzyme inhibitors from pungent constituents of ginger. Thromb Res 2003;111:259-265

21. Kiuchi F, Iwakami S, Shibuya M, Hanaoka F, Sankawa U. Inhibition of prostaglandin and leukotriene biosynthesis by gingerols and diarylheptanoids. Chem Pharm Bull (Tokyo) 1992:40:387-391.

22. Tjendraputra $E$, Tran $V H$, Liu-Brennan $D$, Roufogalis BD, Duke CC. Effect of ginger constituents and synthetic analogues on cyclooxygenase-2 enzyme in intact cells. Bioorg Chem 2001; 29:156-163.

23. Surh YJ, Lee E, Lee JM. Chemoprotective properties of some pungent ingredients present in red pepper and ginger. Mutat Res 1998;402:259-267

24. Ojewole JA. Analgesic, antiinflammatory and hypoglycaemic effects of ethanol extract of Zingiber officinale (Roscoe) rhizomes (Zingiberaceae) in mice and rats. Phytother Res 2006;20:764-772.

25. Park KK, Chun KS, Lee JM, Lee SS, Surh YJ. Inhibitory effects of [6]-gingerol, a major pungent principle of ginger, on phorbol ester-induced inflammation, epidermal ornithine decarboxylase activity and skin tumor promotion in ICR mice. Cancer Lett 1998;129:139-144

26. Suekawa M, Aburada M, Hosoya E. Pharmacological studies on ginger. II. Pressor action of (6)-shogaol in anesthetized rats, or hindquarters, tail and mesenteric vascular beds of rats. $J$ Pharmacobiodyn 1986:9:842-852.

27. Thomson M, Al-Qattan KK, Al-Sawan SM, Alnaqeeb MA, Khan I, Ali M. The use of ginger (Zingiber officinale Rosc.) as a potential anti-inflammatory and antithrombotic agent. Prostaglandins Leukot Essent Fatty Acids 2002;67:475-478.

28. Kim M, Miyamoto S, Yasui Y, Oyama T, Murakami A, Tanaka T. Zerumbone, a tropical ginger sesquiterpene, inhibits colon and lung carcinogenesis in mice. Int J Cancer 2009;124:264-271.

29. Manju V, Nalini N. Chemopreventive efficacy of ginger, a naturally occurring anticarcinogen during the initiation, postinitiation stages of 1,2 dimethylhydrazine-induced colon cancer. Clin Chim Acta 2005;358:60-67.

30. Yoshimi N, Wang A, Morishita Y, et al. Modifying effects of fungal and herb metabolites on azoxymethane-induced intestinal carcinogenesis in rats. Jpn J Cancer Res 1992;83:1273-1278.

31. Dias MC, Spinardi-Barbisan AL, Rodrigues MA, de Camargo JL, Teran E, Barbisan LF. Lack of chemopreventive effects of ginger on colon carcinogenesis induced by 1,2-dimethylhydrazine in rats. Food Chem Toxicol 2006;44:877-884.

32. Jiang $Y$, Turgeon $D K$, Wright $B D$, et al. Effect of ginger root on cyclooxygenase-1 and 15-hydroxyprostaglandin dehydrogenase expression in colonic mucosa of humans at normal and increased risk for colorectal cancer. Eur J Cancer Prev 2012;5:455-460.

33. Zick SM, Turgeon DK, Vareed SK, et al. Phase II study of the effects of ginger root extract on eicosanoids in colon mucosa in people at normal risk for colorectal cancer. Cancer Prev Res (Phila) 2011;4:1929-1937.

34. Zick SM, Djuric Z, Ruffin MT, et al. Pharmacokinetics of 6 gingerol, 8-gingerol, 10-gingerol, and 6-shogaol and conjugate metabolites in healthy human subjects. Cancer Epidemiol Biomarkers Prev 2008;17:1930-1936.

35. U.S. Department of Health and Human Services $\mathrm{NCl}$. Commmon Terminology Criteria for Adverse Events (CTCAE). 2009 September 15, 2009 v4.02 [cited 2013 January 22]; Version 4.0:[Available from: http://www.acrin.org/Portals/0/ Administration/Regulatory/CTCAE_4.02_2009-0915_QuickReference_5 $\times 7$.pdf

36. Yang $P$, Chan $D$, Felix $E$, et al. Determination of endogenous tissue inflammation profiles by LC/MS/MS: COX- and LOXderived bioactive lipids. Prostaglandins Leukot Essent Fatty Acids 2006;75:385-395.

37. Vareed SK, Kakarala M, Ruffin MT, et al. Pharmacokinetics of curcumin conjugate metabolites in healthy human subjects. Cancer Epidemiol Biomarkers Prev 2008;17:1411-1417.

38. Buczynski MW, Stephens DL, Bowers-Gentry RC, Grkovich A, Deems RA, Dennis EA. TLR-4 and sustained calcium agonists synergistically produce eicosanoids independent of protein synthesis in RAW264.7 cells. J Biol Chem 2007;282:2283422847.

39. Krishnan K, Ruffin MT, Normolle D, et al. Colonic mucosal prostaglandin E2 and cyclooxygenase expression before and after low aspirin doses in subjects at high risk or at normal risk for colorectal cancer. Cancer Epidemiol Biomarkers Prev 2001; 10:447-453.

40. Flynn DL, Rafferty MF, Boctor AM. Inhibition of human neutrophil 5-lipoxygenase activity by gingerdione, shogaol, capsaicin and related pungent compounds. Prostaglandins Leukot Med 1986;24:195-198.

41. Lantz RC, Chen GJ, Sarihan M, Solyom AM, Jolad SD, Timmermann BN. The effect of extracts from ginger rhizome on inflammatory mediator production. Phytomedicine 2007:14:123-128.

42. van Breemen RB, Tao Y, Li W. Cyclooxygenase-2 inhibitors in ginger (Zingiber officinale). Fitoterapia 2011;82:38-43.

43. Kim SO, Chun KS, Kundu JK, Surh YJ. Inhibitory effects of [6]gingerol on PMA-induced COX-2 expression and activation of NF-kappaB and p38 MAPK in mouse skin. Biofactors 2004;21:27-31. 
44. Jolad SD, Lantz RC, Chen GJ, Bates RB, Timmermann BN. Commercially processed dry ginger (Zingiber officinale): Composition and effects on LPS-stimulated PGE2 production. Phytochemistry 2005;66:1614-1635.

45. Han YA, Song CW, Koh WS, et al. Anti-inflammatory effects of the Zingiber officinale roscoe constituent 12-dehydrogingerdione in lipopolysaccharide-stimulated Raw 264.7 cells. Phytother Res 2013;27:1200-1205.

46. Li $F$, Nitteranon $V$, Tang $X$, et al. In vitro antioxidant and antiinflammatory activities of 1-dehydro-[6]-gingerdione, 6-shogaol, 6-dehydroshogaol and hexahydrocurcumin. Food Chem 2012;135:332-337.

47. Ha SK, Moon E, Ju MS, et al. 6-Shogaol, a ginger product, modulates neuroinflammation: A new approach to neuroprotection. Neuropharmacology 2012;63:211-223.

48. Black CD, Herring MP, Hurley DJ, O'Connor PJ. Ginger (Zingiber officinale) reduces muscle pain caused by eccentric exercise. J Pain 2010;11:894-903.

49. Drozdov VN, Kim VA, Tkachenko EV, Varvanina GG. Influence of a specific ginger combination on gastropathy conditions in patients with osteoarthritis of the knee or hip. J Altern Complement Med (NY) 2012;18:583-588.

50. Liggett JL, Zhang X, Eling TE, Baek SJ. Anti-tumor activity of non-steroidal anti-inflammatory drugs: Cyclooxygenase-independent targets. Cancer Lett 2014:346:217-224.

51. Baliga MS, Haniadka R, Pereira MM, et al. Update on the chemopreventive effects of ginger and its phytochemicals. Crit Rev Food Sci Nutr 2011;51:499-523.

52. Butt MS, Sultan MT. Ginger and its health claims: Molecular aspects. Crit Rev Food Sci Nutr 2011;51:383-393.

53. Citronberg J, Bostick RM, Ahearn TU, et al. Effects of ginger supplementation on cell cycle biomarkers in the normalappearing colonic mucosa: Results from a pilot, randomized, controlled trial. Cancer Prev Res (Phila) 2013;4:271-281.

SUPPORTING INFORMATION

Additional supporting information may be found in the online version of this article at the publisher's web-site. 